\title{
Microencapsulation of citronella oil for solar-activated controlled release as an insect repellent
}

\author{
António D. Ribeiro ${ }^{\mathrm{a}}$, Juliana Marques ${ }^{\mathrm{a}}$, Marta Forte ${ }^{\mathrm{a}}$, Filipe C. Correia ${ }^{\mathrm{a}}$, Pier Parpot ${ }^{\mathrm{b}}$, César Oliveira ${ }^{\mathrm{b}}$, \\ Ana I. Pereira ${ }^{c}$, Luísa Andrade ${ }^{c}$, Cátia Azenha $^{c}$, Adélio Mendes $^{c}$, Gonçalo M. Alves ${ }^{d}$, Carla A. Sousa ${ }^{\text {, }}$ \\ Carlos J. Tavares ${ }^{\mathrm{a}, *}$ \\ a Centre of Physics, University of Minho, Campus of Azurém, 4835-386 Guimarães, Portugal \\ ${ }^{b}$ Centre of Chemistry, University of Minho, Campus of Azurém, 4710-057 Braga, Portugal \\ ${ }^{\mathrm{c}}$ LEPABE, Faculty of Engineering of the University of Porto, Rua Roberto Frias s/n, 4200-465 Porto, Portugal \\ d Unit of Medical Parasitology, Global Health and Tropical Medicine, Instituto de Higiene e Medicina Tropical, Universidade Nova de Lisboa, Rua da Junqueira 100, \\ 1349-008 Lisboa, Portugal
}

\section{A R T I C L E I N F O}

\section{Article history:}

Received 21 April 2016

Received in revised form 22 July 2016

Accepted 8 September 2016

\section{Keywords:}

Photocatalysis

Microcapsules

$\mathrm{TiO}_{2}$

Nanoparticles

Controlled release

Mosquito repellent

\begin{abstract}
A B S T R A C T
This study investigates the functionalization of titanium dioxide nanoparticles on the surface of polymeric microcapsules as a mean to control the release of encapsulated citronella through solar radiation. This allows for the release of a mosquito repellent without human intervention, as the sunlight works as a release activator. The $\mathrm{TiO}_{2}$ nanoparticles were synthetized using a modified sol-gel and hydrothermal method, with a crystallite size of the order of $10 \mathrm{~nm}$ and a specific surface area $>250 \mathrm{~m}^{2} / \mathrm{g}$. Transmission electron microscopy observations enabled the confirmation of the mesoporous structure. The nitrogen doping effect and changes in $\mathrm{pH}(\mathrm{pH}=3,6$ and 9$)$ of the precursor solution was studied from photocatalytic and photoluminescence experiments. Polyurethane microcapsules were prepared using a modified interfacial polymerization method. The surface topography of the microcapsules was observed with scanning electron microscopy, while the release efficiency was quantified using gas chromatography coupled with mass spectroscopy. In-vitro bioassays using live mosquitoes further attested the controlled release repellence effect of these photocatalytic microcapsules by inhibition of these vectors. The results showed that functionalizing the microcapsules with nanoparticles on their surface and then exposing them to ultraviolet radiation effectively increased the output of citronella into the air, repelling the mosquitoes.
\end{abstract}

(c) 2016 Elsevier Ltd. All rights reserved.

\section{Introduction}

Microencapsulation has been an area of growing interest and investigation in recent years due to its many applications, such as drug controlled release in pharmaceutical products, crop protection in agriculture, release of nutrients in the food industry and selfhealing surfaces $[1,2]$. Various microencapsulation methods have been reported in the last 15 years [1-5]. In a solvent evaporation process, one of the most common methods, microencapsulation is achieved by dissolving the capsule wall material in an organic solvent, together with the core material, creating a water immiscible solution, which is then emulsified in water. Once the solvent evaporates, microcapsules are produced. However, besides being quite expensive, this method requires complex processes and only

\footnotetext{
* Corresponding author.

E-mail address: ctavares@fisica.uminho.pt (C.J. Tavares).
}

facilitates encapsulation when using hydrophobic polymers [6-10]. In-situ polymerization is accomplished by creating an emulsion, containing the monomers in the contiguous phase with the core material dispersed. The monomers then react, encapsulating the core material. Despite being difficult to achieve a good equilibrium, this technique allows the encapsulation of highly reactive materials [5,11-13]. Hence, interfacial polymerization emerged as an easy method to prepare microcapsules. This method allows a high degree of control over the physical/chemical properties using mild reaction conditions. It involves the condensation reactions between two monomers, much like in-situ polymerization; however, in this case, one of the monomers is dissolved in the core material. Besides being a relatively simple and inexpensive method, interfacial polymerization permits a high degree of control on the final product by varying the reaction parameters [14-17].

In this work, citronella oil was encapsulated in polyurethane microcapsules, following the reaction of a diol with an isocyanate. Citronella was chosen since it is an affordable repellent, while 
being natural occurring, non-toxic and easy to handle [18,19]. Polyurethane was the polymer of choice for the micro reservoir due to the high mechanical resistance of the resulting microcapsules.

\section{Experimental}

\subsection{Materials}

Titanium (IV) isopropoxide (>99\%, Sigma-Aldrich), P25 nanoparticles (Evonik, for comparison), propyl alcohol (>98\%, Sigma Aldrich), ethylenediamine ( $>99.5 \%$, Sigma Aldrich), hydrochloric acid (37\%, Sigma), sodium hydroxide (Sigma Aldrich), 1,4-butenediol (Sigma Aldrich), Arabic gum (Sigma Aldrich), chlorobenzene (Sigma Aldrich), TDI prepolymer Desmodur DL-75 (Bayer Materials Science), citronella oil java (Sigma Aldrich).

\subsection{Synthesis of the $\mathrm{TiO}_{2}$ powders}

The $\mathrm{TiO}_{2}$ nanoparticles were synthesized by a sol-gel method followed by a hydrothermal treatment. A propyl alcohol solution in water (1:10) was prepared, and its $\mathrm{pH}$ adjusted using $\mathrm{NaOH}(1 \mathrm{M})$ or $\mathrm{HNO}_{3}(3 \mathrm{M})$. The nanoparticles were prepared by dissolving $2 \mathrm{ml}$ of titanium isopropoxide in $2.5 \mathrm{ml}$ of the previous alcohol/water solution and, for nitrogen doping, subsequently adding $6 \mathrm{ml}$ of ethylenediamine. The reaction was carried out under gentle stirring for $48 \mathrm{~h}$. Six samples were made, where the effect of nitrogendoping and $\mathrm{pH}$ was studied, being the $\mathrm{pH}$ adjusted to 3, 6 and 9 for each set of, doped $\left(\mathrm{NTiO}_{2}\right)$ and undoped $\left(\mathrm{TiO}_{2}\right)$ powders. After synthesis, the nanopowders were calcined at $200^{\circ} \mathrm{C}$ for $2 \mathrm{~h}$, followed by centrifugation to collect them and washed three times with propyl alcohol between centrifugations, and finally dried for $6 \mathrm{~h}$ at $60^{\circ} \mathrm{C}$.

\subsection{Synthesis of the polymeric microcapsules}

The microcapsules were prepared by an interfacial polymerization method, where an oil in water $(\mathrm{o} / \mathrm{w})$ emulsion is created using a mechanical stirrer. The microcapsules wall forms in the interface between the two phases, through the reaction of 1,4-butene-diol (water phase) with isocyanate (organic oil phase). The encapsulation of citronella was achieved by dissolving $2 \mathrm{~g}$ of isocyanate in $5 \mathrm{ml}$ of chlorobenzene. Then, this solution was mixed with $2 \mathrm{ml}$ of citronella and added to $120 \mathrm{ml}$ aqueous solution of Arabic gum $(10 \%, w / v)$, while stirring at $600 \mathrm{rpm}$. Lastly, the temperature was raised to $65^{\circ} \mathrm{C}$ and $2.5 \mathrm{ml}$ of 1,4 -butene-diol was added to create the polymer. The resulting microcapsules were rinsed several times with water to remove any unreacted reagent.

\subsection{Photocatalytic activity}

In order to evaluate the photocatalytic activity of the different nanoparticles samples, the photocatalytic oxidation of methylene blue (MB) in the presence of the $\mathrm{TiO}_{2}$ nanoparticles under UV irradiation was studied. The experiments were carried out by suspending $1.75 \mathrm{mg}$ of nanoparticles in an aqueous methylene blue solution $\left(10^{-5} \mathrm{M}\right)$ in a quartz cell $(40 \mathrm{~mm} \times 40 \mathrm{~mm} \times 10 \mathrm{~mm})$, under UV radiation centred at $365 \mathrm{~nm}$ with a high power LED source (Thorlabs, $700 \mathrm{~mA}$ ), with an average irradiance of $\sim 4 \mathrm{~mW} \mathrm{~cm}^{-2}[20,21]$. The rate of photo-degradation of $\mathrm{MB}$ is related to the variation in intensity of the absorption peak of this chromophore at $665 \mathrm{~nm}$, which was analyzed using a spectrophotometer (ScanSpec UV-Vis, ScanSci) in the range of $300-900 \mathrm{~nm}$.
The kinetics of the photocatalytic degradation of MB is a pseudofirst-order reaction, expressed according to the equation [20-23]:

$\ln \left(\frac{C}{C_{0}}\right)=-k t$

where $C_{0}$ and $C$ represents the dye's initial concentration and at the time $t$, respectively, which is proportional to its optical absorbance, and $k$ is the first-order constant of the reaction.

\subsection{Detection of hydroxyl radicals}

The production of hydroxyl radicals $(\bullet \mathrm{OH})$ during the photocatalysis reaction is linked to the quantitative production of 7-hydroxycoumarin (7HC, or Umbelliferone) from coumarin, since the latter reacts with $\bullet \mathrm{OH}$ radicals to produce the former, a highly fluorescent sub-product which shows a photoluminescence (PL) signal at $456 \mathrm{~nm}$ [24]. At room temperature, $12 \mathrm{mg}$ of nanoparticles were dispersed in $12 \mathrm{ml}$ of coumarin aqueous solution $\left(10^{-3} \mathrm{M}\right.$, $\mathrm{pH}=3)$ in a quartz cell $(40 \mathrm{~mm} \times 40 \mathrm{~mm} \times 10 \mathrm{~mm})$. Initially the solution was kept in the dark to establish adsorption-desorption equilibrium, then, at given intervals of UV irradiation centred at $365 \mathrm{~nm}$ with a high power LED source (Thorlabs, $700 \mathrm{~mA}$ ), the suspension was centrifuged and its PL signal analyzed on the spectrophotometer. This excitation wavelength was chosen in order to be near the $S_{0} \rightarrow S_{1}$ transition of the neutral form of the 7-hydroxyl group.

\subsection{Characterization methods}

The citronella output yield from within the microcapsules was measured through gas chromatography coupled with mass spectrometry (GC-MS) analysis, using a Varian 4000 Performance apparatus, equipped with a CP8944 VF-5 column and an ion trap mass spectrometer as detector. The carrier gas was helium, at a flow rate of $1 \mathrm{ml} \mathrm{min}^{-1}$. Column temperature was initially $40^{\circ} \mathrm{C}$, and then gradually increased to $270^{\circ} \mathrm{C}$ at $8^{\circ} \mathrm{C} \mathrm{min}^{-1}$. For GC-MS detection an electron impact ionization system was used with ionization energy of $70 \mathrm{eV}$.

The crystalline structure of the $\mathrm{TiO}_{2}$ nanoparticles was characterized using X-ray diffraction analysis (XRD, Bruker D8 Discover diffractometer) using $\mathrm{CuK}_{\alpha}$ radiation, while the morphological properties were studied using a scanning electron microscope (SEM, NanoSEM-FEI Nova 200) at SEMAT/UM. To assess the nanoparticles specific surface area, nitrogen adsorption tests based on the Brunauer-Emmett-Teller (BET) theory were made at University of Porto, using the Quantachrome Instruments Autosorb-1. Also, reflectance experiments allowed for the calculation of the band-gap energy of the semiconductor material (nanoparticles) using a Shimadzu spectrophotometer UV-2501 PC. For the transmission electron microscopy (TEM) analysis, a Hitachi model H9000 NAR equipment from the University of Aveiro was used. Finally, the final product (microcapsules functionalized with nanoparticles) was tested using live mosquitoes at the Portuguese Institute of Hygiene and Tropical Medicine (IHMT) in Lisbon, to access the repellent properties of the photocatalytic microcapsules.

\subsection{In-vitro tests}

\subsubsection{Mosquito colony}

A colony of Anopheles stephensi (Liston, 1901) was kept under standard conditions for an undetermined number of generations, at $27 \pm 2{ }^{\circ} \mathrm{C}, 70 \pm 5 \%$ relative humidity and a day/night cycle of $12 \mathrm{~h}-12 \mathrm{~h}$, at the IHMT insectarium. 


\subsubsection{Laying deterrent effect}

To study the laying deterrent effect, three microcapsules suspensions in dechlorinated tap water were studied (30\%, 15\% and 7.5\%). An undetermined number of females between 3 and 4 days old was given the opportunity to feed on BALB/c (Mus musculus), previously anaesthetized under European legislation (86/609/EEC). After feeding, ten engorged mosquito females and five males were transferred to the test cage $(20 \mathrm{~cm} \times 20 \mathrm{~cm} \times 20 \mathrm{~cm})$. After 2 days, two Petri dishes containing $50 \mathrm{ml}$ of water (control) and microcapsules suspension (test) were introduced in the cage. The test glasses were subjected to $60 \mathrm{~min}$ of UV-A irradiation prior to the tests. After $24 \mathrm{~h}$, the amount of eggs in each glass was counted. Three tests were conducted for each dosage of microcapsules.

\subsubsection{Tunnel system repellent tests}

To evaluate the repellent capacity, a tunnel system was used according to WHO recommendations [25]. This method allows the evaluation of the mosquito behaviour during its search for a host in the presence of treated materials with repellent capabilities, providing information on repellence and blood feeding inhibition [26]. The system is composed of two rectangular acrylic boxes $(25 \mathrm{~cm} \times 21 \mathrm{~cm} \times 60 \mathrm{~cm})$, designated as control and test. Each box is divided in two equal chambers (A and B). In chamber B is introduced a specimen of Rattus norvegicus, Wister strain, anesthetized and immobilized, as a bait for blood feeding. At chamber A, 100 nonfed female $A$. stephensi, 3-5 days old, were released. Dividing the two chambers was a piece of cloth $(25 \mathrm{~cm} \times 21 \mathrm{~cm})$, with 30 holes of $1 \mathrm{~cm}$ in diameter each. For the test box, the piece of cloth was previously dipped in citronella-loaded photocatalytic microcapsules, obtaining an homogeneous loading in the textile, while for the control box only the described plain untreated cloth was used. Each of the four tests took place during $60 \mathrm{~min}$, registering the number of mosquitoes passing from chamber A to chamber B; the test cloths were subjected to $60 \mathrm{~min}$ of UV-A irradiation prior to the tests. At the end of the test, the number of live and dead, fed and non-fed mosquitoes in each chamber was counted. Using this data, the blood feeding reduction index (BFI) and the repellence index (IRE) were calculated, according to:

$\mathrm{BFI}=100-\frac{\text { treated } \times 100}{\text { control }}$

where treated represents the proportion of fed females captured in the test tunnel and control represents the proportion of fed females captured in the control tunnel.

IRE $=100-\frac{\text { treated } \times 100}{\text { control }}$

where treated represents the proportion of females that reached compartment $B$ in the test tunnel and control represents the proportion of females that reached compartment $\mathrm{B}$ in the control tunnel.

\section{Results and discussion}

\subsection{XRD analysis}

Fig. 1 shows the XRD patterns for the six different nanoparticle samples, synthesized with varying $\mathrm{pH}\left(3,6\right.$ and 9), doped $\left(\mathrm{NTiO}_{2}\right)$ and undoped $\left(\mathrm{TiO}_{2}\right)$. All samples exhibit characteristic diffraction peaks associated with the anatase structure, with very small crystallite size, under $10 \mathrm{~nm}$, determined by Rietveld refinement. With an increase in $\mathrm{pH}$ of the titanium precursor solution the undoped powders become more crystalline. The broader peaks for the $\mathrm{N}$ doped nanoparticles suggests a smaller crystallite size than that of non-doped nanoparticles.

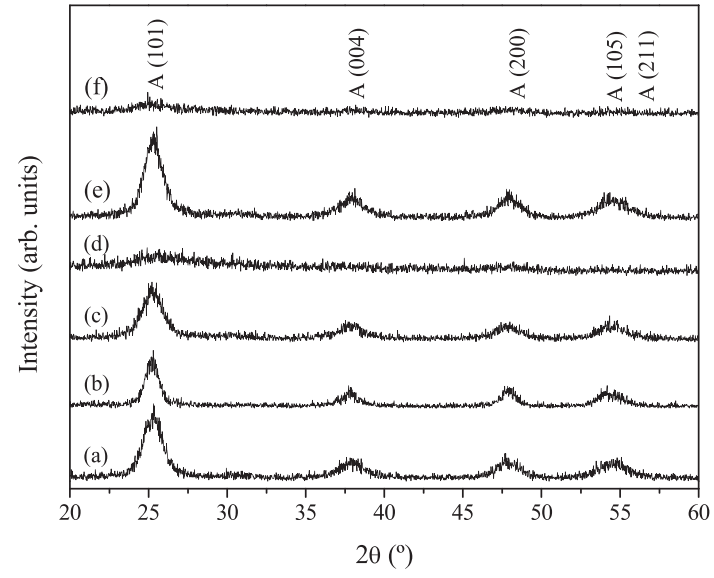

Fig. 1. Diffraction patterns for (a) $\mathrm{TiO}_{2}-\mathrm{pH} 3$, (b) $\mathrm{NTiO}_{2}-\mathrm{pH} 3$, (c) $\mathrm{TiO}_{2}-\mathrm{pH}$, (d) $\mathrm{NTiO}_{2}-$ pH6, (e) $\mathrm{TiO}_{2}$-pH9 and (f) $\mathrm{NTiO}_{2}$-pH9 nanopowders.

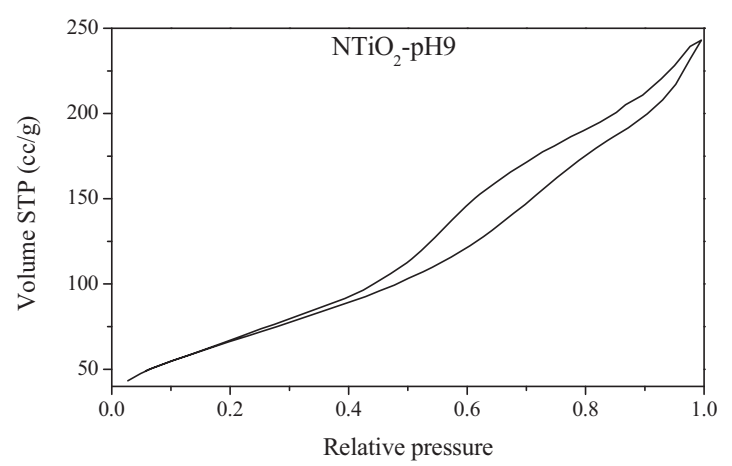

Fig. 2. BET analysis of the $\mathrm{NTiO}_{2}$-pH9 sample showing the volume at standard temperature and pressure (STP) as a function of the relative pressure.

\subsection{Surface area assessment (BET analysis)}

BET analysis allows the estimation of the pore volume distribution and the specific surface area for each sample, based on nitrogen adsorption tests. From Fig. 2 it is concluded that sample $\mathrm{NTiO}_{2}-\mathrm{pH} 9$ is a type $\mathrm{V}$ material, since there is not a clear evidence on the transition point from monolayer to multilayer gas adsorption [27]. The hysteresis phenomena indicates that this sample is a mesoporous material, with pores in the range of $2-10 \mathrm{~nm}$, indicative of a high surface area. From Fig. 3 it is possible to observe the cumulative

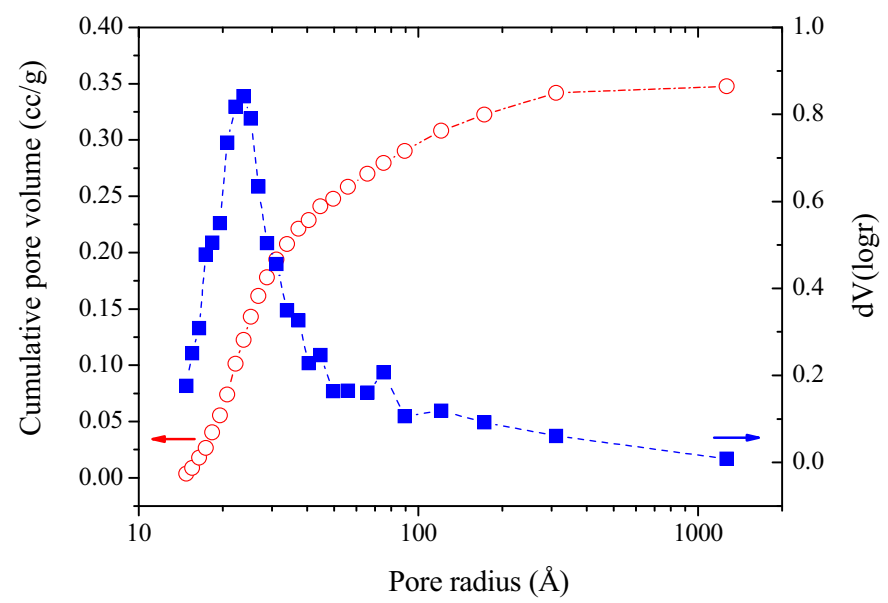

Fig. 3. Cumulative pore volume distribution and its differentiation, $\mathrm{d} V(\log r)$, in respect to the pore radius distribution, for sample $\mathrm{NTiO}_{2}-\mathrm{pH} 9$. 

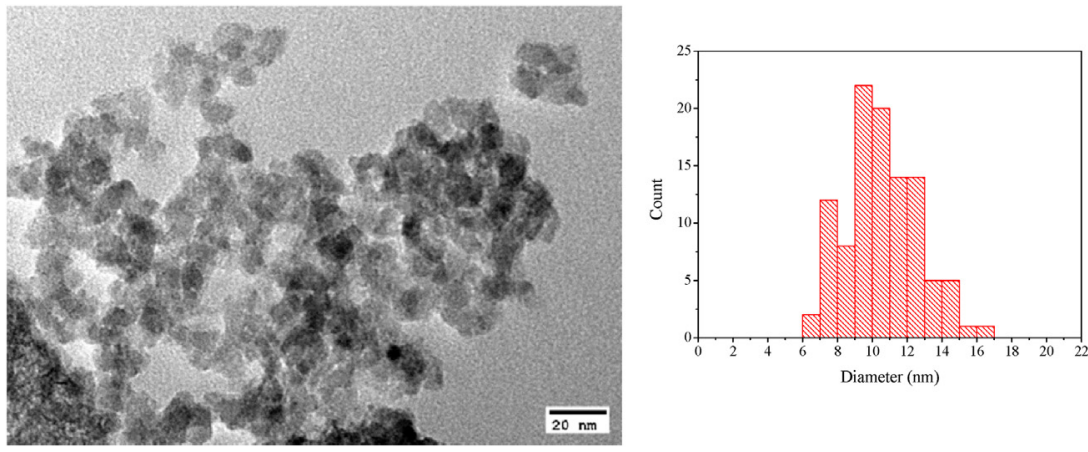

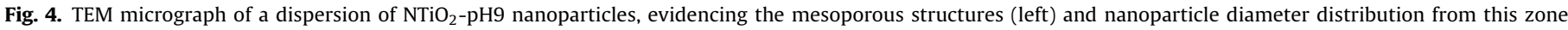
(right).

Table 1

Specific surface area for the different nanoparticle samples, including Evonik P25 as a reference.

\begin{tabular}{|c|c|c|}
\hline \multirow[t]{2}{*}{$\mathrm{TiO}_{2}$ sample } & \multicolumn{2}{|c|}{ Specific surface area $\left(\mathrm{m}^{2} \mathrm{~g}^{-1}\right)$} \\
\hline & Undoped & Doped \\
\hline pH3 & 206 & 216 \\
\hline pH6 & 168 & 134 \\
\hline $\mathrm{pH} 9$ & 206 & 287 \\
\hline P25 & \multicolumn{2}{|c|}{50} \\
\hline
\end{tabular}

pore volume distribution as a function of the pore radius associated with sample $\mathrm{NTiO}_{2}-\mathrm{pH} 9$. From this figure it was determined an average pore radius of $2.22 \mathrm{~nm}$ and a pore volume of $0.348 \mathrm{~cm}^{3} / \mathrm{g}$. For this sample the specific surface area is $287 \mathrm{~m}^{2} / \mathrm{g}$, as listed in Table 1.

As seen in Table 1, all samples present a much larger specific surface area in comparison to the P25 standard nanoparticles (from Evonik), being that of $\mathrm{NTiO}_{2}-\mathrm{pH} 9$ nearly six times larger. The reason for this is related to the fact that the $\mathrm{NTiO}_{2}$ particles have crystallites below $10 \mathrm{~nm}$ (as seen in the previous section and in the following one), while for P25 the crystalline domains are around $30 \mathrm{~nm}$. Additionally, $\mathrm{NTiO}_{2}$ powders consists essentially of the anatase phase, whereas for P25 it has about $20 \%$ of the rutile polymorph, which has a higher density and bigger crystallite size, hence lower ratio of particle diameter per volume ( $\sim 30$ times lower), when compared to the $\mathrm{NTiO}_{2}$ particles reported here. The lower specific surface area values for the nanoparticles synthesized with $\mathrm{pH} 6$ might be attributed to agglomeration, since this is less likely to happen in the positively or negatively charged $\mathrm{pH} 3$ and $\mathrm{pH} 9$ samples. $\mathrm{N}$-doping led to an increase in surface area for the nanoparticles synthetized at $\mathrm{pH} 3$ and $\mathrm{pH} 9$.

\subsection{TEM analysis}

In order to confirm the mesoporous structure of the synthesized $\mathrm{TiO}_{2}$ nanoparticles, TEM analysis was endured, where dispersions of nanoparticles were placed on copper/carbon grids. Fig. 4 shows a distribution of nanoparticles from sample $\mathrm{NTiO}_{2}-\mathrm{pH}$, where it can be seen that the particles have an average diameter of $\sim 10 \mathrm{~nm}$, as it is discerned in the histogram associated with this micrograph. Some particles seem to coalesce or overlap, hence producing a larger domain $(>12 \mathrm{~nm}$ ). In Fig. 5 bright- and dark-field images of another dispersion from the same sample is observed, at a lower magnification. From the contrast in the dark-field image it is possible to discern the small crystallites, which corroborates with the previous analysis, as well as it is consistent with the Rietveld refinement results from the X-ray diffraction data, discussed in Section 3.1.

\subsection{Gap energy evaluation}

The band-gap energy, associated with absorbance threshold, was calculated using diffuse reflectance analysis. From Table 2, and contrary to what was expected, $\mathrm{N}$-doping within $\mathrm{TiO}_{2}$ actually increased the gap energy, probably because the dopant nitrogen

Table 2

Band gap energy values for the different synthesized nanoparticles.

\begin{tabular}{lll}
\hline $\mathrm{TiO}_{2}$ sample & \multicolumn{2}{l}{ Gap energy $(\mathrm{eV})$} \\
\cline { 2 - 3 } & Undoped & Doped \\
\hline $\mathrm{pH} 3$ & 3.09 & 3.16 \\
$\mathrm{pH} 6$ & 3.17 & 3.24 \\
$\mathrm{pH} 9$ & 3.25 & 3.26 \\
\hline
\end{tabular}

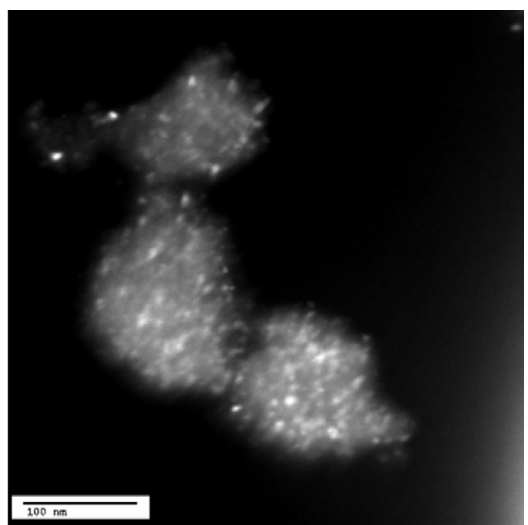

Fig. 5. TEM micrographs in bright- (left) and dark-field (right) relative to the same dispersion of $\mathrm{NTiO}_{2}$-pH9 nanoparticles. 


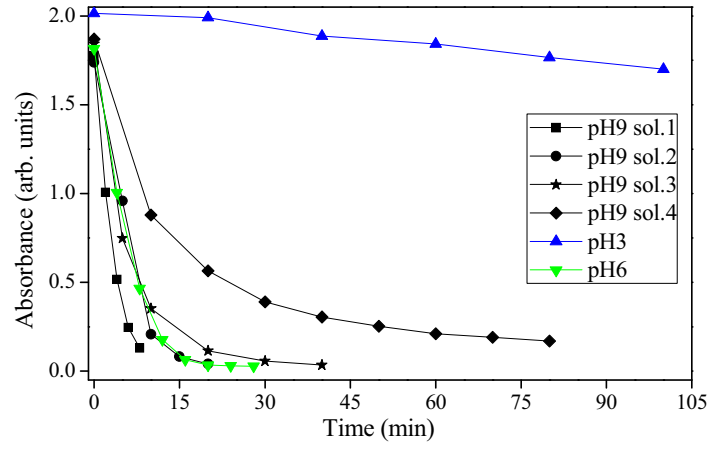

Fig. 6. UV-vis absorption variation of $\mathrm{MB}\left(10^{-5} \mathrm{M}\right)$ solution at $665 \mathrm{~nm}$ measured in the dark as a function of time for the $\mathrm{N}$-doped nano- $\mathrm{TiO}_{2}$ powder, synthesized at different $\mathrm{pH}$.

atoms occupy interstitial positions in the lattice, instead as substituents on oxygen atomic sites. Despite the higher band-gap energy, the doped samples present a higher photocatalytic activity when compared to the undoped counterparts, as shown in the next sub-section.

\subsection{Evaluation of the photocatalytic activity of the $\mathrm{TiO}_{2}$ powders}

\subsubsection{Adsorption of methylene blue on $\mathrm{TiO}_{2}$}

A solution of methylene blue $\left(10^{-5} \mathrm{M}\right)$ was stirred with different $\mathrm{TiO}_{2}$ nanoparticles $\left(0.15 \mathrm{~g} \mathrm{~L}^{-1}\right)$ in the dark to ensure total adsorption of the dye. The MB concentration of the solution can be linked with the absorption peak at $665 \mathrm{~nm}$, which was monitored using a spectrophotometer during a period of time, as plotted in Fig. 6. The $\mathrm{NTiO}_{2}-\mathrm{pH} 3$ nanoparticles were those with less methylene adsorbed at the surface, as opposed to the $\mathrm{NTiO}_{2}$-pH9 sample which showed a high adsorption rate. In fact, the dye adsorption rate for the $\mathrm{NTiO}_{2}$-pH9 sample was so high that it completely adsorbed three solutions (sol. 1 through 3 ), coming to a halt at the fourth (sol. 4). This high discrepancy in the adsorption rates of the three samples can be explained by the $\mathrm{pH}$ effect on the synthesis of the nanoparticles. It is believed that the nanoparticles synthesized at $\mathrm{pH}$ lower than the point of zero charge $(\mathrm{PZC}=6.8)$ have positive charges at the surface, while the ones synthesized at higher $\mathrm{pH}$ values have negative charges. Being that the methylene blue is a positively charged molecule, it is attracted to the negatively charged $\mathrm{NTiO}_{2}-\mathrm{pH} 9$ nanoparticles and repelled by the $\mathrm{NTiO}_{2}-\mathrm{pH} 3$, explaining the difference in the adsorption rates.

\subsubsection{Photocatalysis assays}

Photocatalytic degradation reactions of MB under UV-A were investigated using the doped and non-doped nanoparticles, as well as P25 as reference, as shown in Figs. 7 and 8. The photocatalytic degradation is a pseudo-first-order reaction and its kinetics, $k$ values (Eq. (1)), are given in Table 3. In contrast with the non-doped samples, the photocatalytic activity of the nitrogen doped nanoparticles varied greatly, being the $\mathrm{NTiO}_{2}-\mathrm{pH} 9$ the only to surpass the

Table 3

Rate constant $(k)$ of the $\mathrm{MB}\left(10^{-5} \mathrm{M}\right)$ solution for the different $\mathrm{TiO}_{2}$ powders; Evonik $\mathrm{P} 25$ is used as a reference.

\begin{tabular}{ll}
\hline Samples & $k$ values $\left(\times 10^{-3} \mathrm{~min}^{-1}\right)$ \\
\hline $\mathrm{TiO}_{2}$-pH3 & 7.1 \\
$\mathrm{TiO}_{2}$-pH6 & 7.1 \\
$\mathrm{TiO}_{2}$-pH9 & 7.5 \\
$\mathrm{NTiO}_{2}$-pH3 & 8.0 \\
$\mathrm{NTiO}_{2}$-pH6 & 2.8 \\
$\mathrm{NTiO}_{2}$-pH9 & 54 \\
$\mathrm{P} 25$ & 17 \\
\hline
\end{tabular}

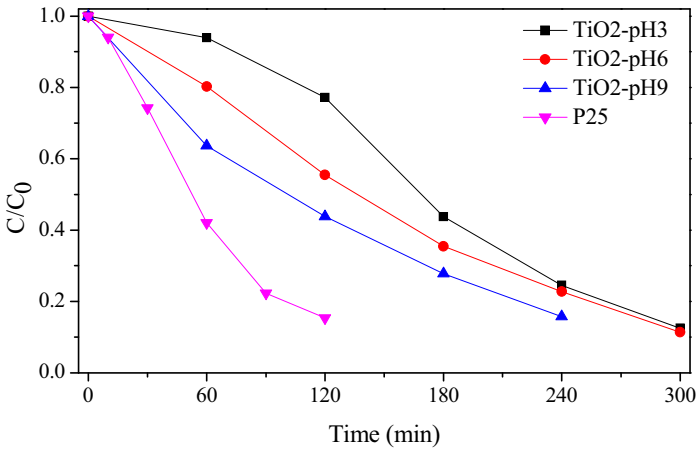

Fig. 7. Photo-degradation of $\mathrm{MB}\left(10^{-5} \mathrm{M}\right)$ solution as a function of UV-A irradiation time for undoped nano- $\mathrm{TiO}_{2}$ powders synthesized at different $\mathrm{pH}$; $\mathrm{P} 25$ standard is used for comparison.

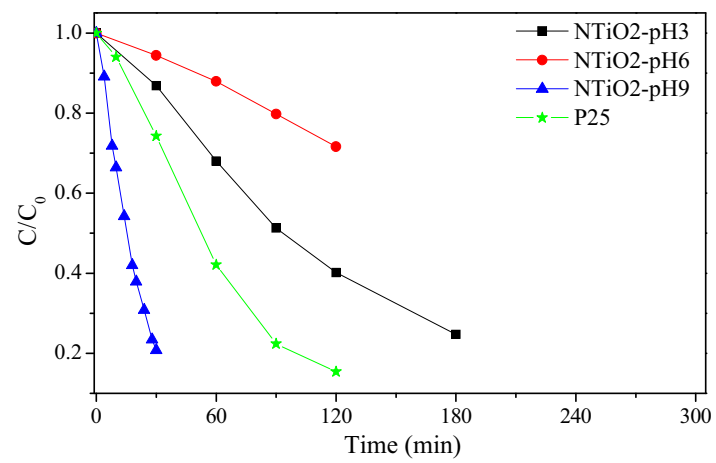

Fig. 8. Photo-degradation of $\mathrm{MB}\left(10^{-5} \mathrm{M}\right)$ solution as a function of UV-A irradiation time for $\mathrm{N}$-doped nano- $\mathrm{TiO}_{2}$ powders synthesized at different $\mathrm{pH}$; $\mathrm{P} 25$ standard is used for comparison.

commercially available P25, with a reaction kinetic nearly three times higher. This is believed to occur due to the negative charges present in the nanoparticles surface that attract the positively charged MB molecule.

\subsection{Photoluminescence of coumarin}

Under UV radiation, the nanoparticles generate electrons $\left(\mathrm{e}^{-}\right)$ and holes $\left(\mathrm{h}^{+}\right)$pairs through redox mechanisms, which in turn react with the $\mathrm{MB}$ dye. In an aqueous medium, $\mathrm{h}^{+}$then reacts with $\mathrm{H}_{2} \mathrm{O}$ and generate $\bullet \mathrm{OH}$ radicals. Coumarin reacts with hydroxyl radicals and yields various sub-products, being a particular one, 7-hydroxycoumarin, strongly fluorescent, as follows:

Coumarin $+{ }^{\bullet} \mathrm{OH} \rightarrow$ 7-hydroxycoumarin

The 7-hydroxycoumarin fluorescence signal can be used to determine the quantity of $\bullet \mathrm{OH}$ generated in the reaction, due to the strong oxidation ability of these radicals $(2.8 \mathrm{~V}$ vs. SHE) [24], which is than related to the photocatalytic activity of the nanoparticles. Fig. 9(a) shows the changes in PL intensity from the coumarin solution with UV-A irradiation time in the presence of $\mathrm{NTiO}_{2}$-pH9 powder. It is noticeable the increase in the fluorescence intensity over time at $\sim 465 \mathrm{~nm}$. This intense emission band is yielded from the efficient excited-state proton transfer that occurs in aqueous solution, from the deprotonated form of 7-hydroxyl [28]. Hence, this signal can be related to the production of 7-hydroxycoumarin from the reaction of coumarin with the hydroxyl radicals produced during photocatalysis. Fig. 9(b) reveals that the 7-hydroxycoumarin fluorescence intensity increases linearly with time, obeying a pseudo-zero-order reaction rate kinetics. Thus, from the slope of the data presented in Fig. 9(b) it is possible to determine a zero-order rate constant of $2.4 \times 10^{-3} \mathrm{~min}^{-1}$ for 

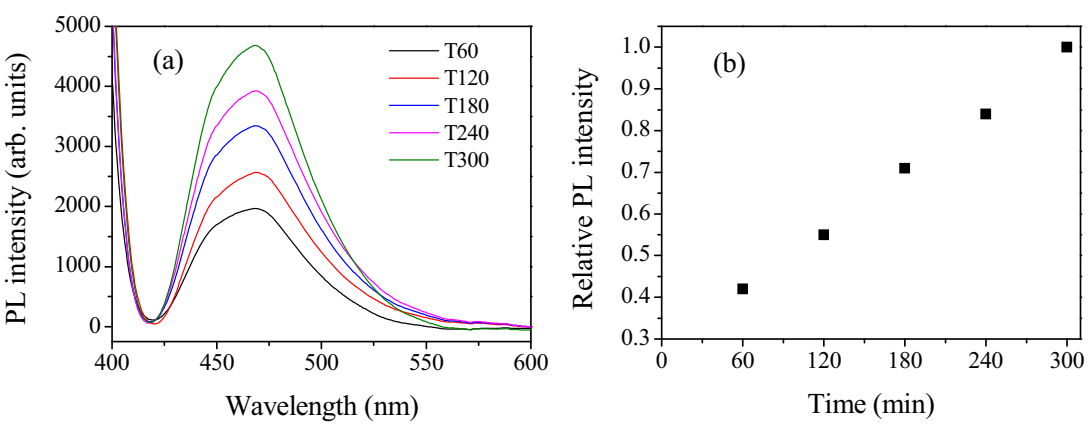

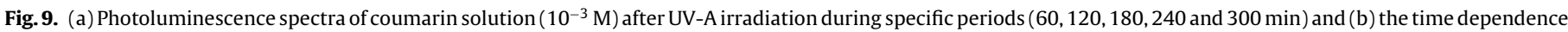
of the photoluminescence intensity of 7-hydroxycoumarin at $456 \mathrm{~nm}$, in the presence of the $\mathrm{NTiO}_{2}$-pH9 powder.

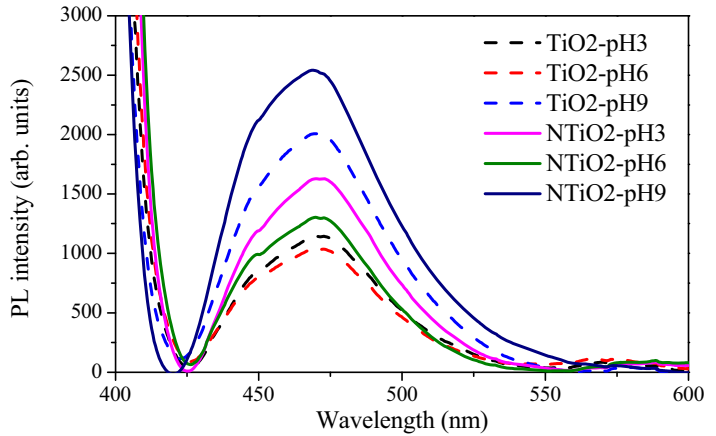

Fig. 10. Photoluminescence spectra of coumarin solution $\left(10^{-3} \mathrm{M}\right)$ after $120 \mathrm{~min}$ of $\mathrm{UV}$-A irradiation in the presence of $\mathrm{N}$-doped and undoped $\mathrm{TiO}_{2}$ powders.

the photooxidation of coumarin, which in turn is related with the photocatalytic activity of the $\mathrm{NTiO}_{2}-\mathrm{pH} 9$ nanoparticles.

In order to investigate the effect of $\mathrm{pH}$ during $\mathrm{TiO}_{2}$ nanoparticle synthesis on the formation rate of radicals, PL experiments were conducted in the same conditions as $\mathrm{NTiO}_{2}$-pH9 for all other powder samples. By analyzing Fig. 10 it is possible to see that these results are closely related to the photocatalysis assays, being the $\mathrm{NTiO}_{2}$-pH9 sample the one that showed a higher amount of radical production after $120 \mathrm{~min}$; and, as such from this optimization procedure, sample $\mathrm{NTiO}_{2}$-pH9 was subsequently chosen to functionalize the microcapsules, as it is presented in the next section.

\subsection{Microcapsule morphology}

The synthesized polyurethane microcapsules possess a near perfect spherical morphology, with sizes ranging from 50 to $250 \mu \mathrm{m}$, as seen in Fig. 11(a). In some capsules unreacted or subproducts are adsorbed to their external surface. Fig. 11(b) shows the

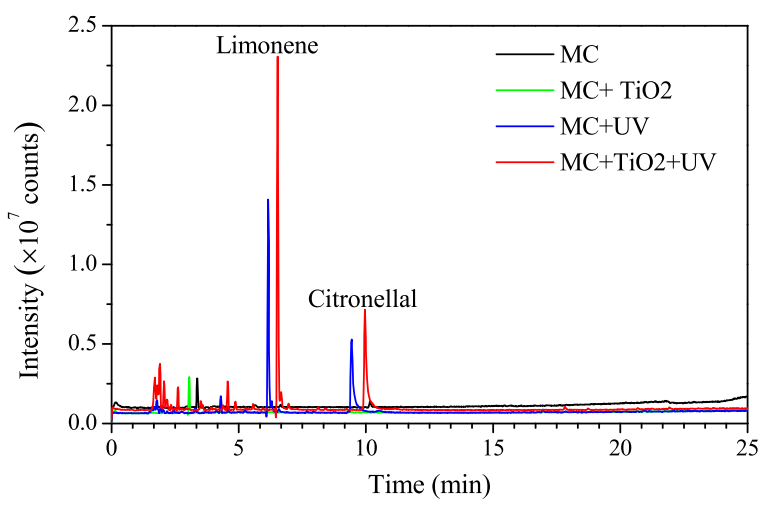

Fig. 12. Chromatograms obtained by GC-MS for microcapsules loaded with citronella, with and without functionalization with N-doped $\mathrm{TiO}_{2} \mathrm{NPs}$ and UVexposure.

microcapsules after being subjected to mechanical forces, exposing their interior. The microcapsules have a hollow interior, with an average wall thickness of $10 \mu \mathrm{m}$.

\subsection{Evaluation of citronella release by GC-MS}

The GC-MS analysis revealed the presence of citronellal and limonene as the main compounds from the output yield (Fig. 12). Four samples were tested to evaluate the output of citronella from the polyurethane microcapsules (MC): (i) microcapsules without nanoparticles (MC); (ii) microcapsules functionalized with nanoparticles $\left(\mathrm{MC}+\mathrm{TiO}_{2}\right)$; (iii) microcapsules without nanoparticles under UV irradiation (MC+UV); and (iv) microcapsules functionalized with nanoparticles under UV irradiation $\left(\mathrm{MC}+\mathrm{TiO}_{2}+\mathrm{UV}\right)$. The nanoparticles used were the optimized $\mathrm{NTiO}_{2}-\mathrm{pH} 9$, since these attained the best photocatalytic activity.
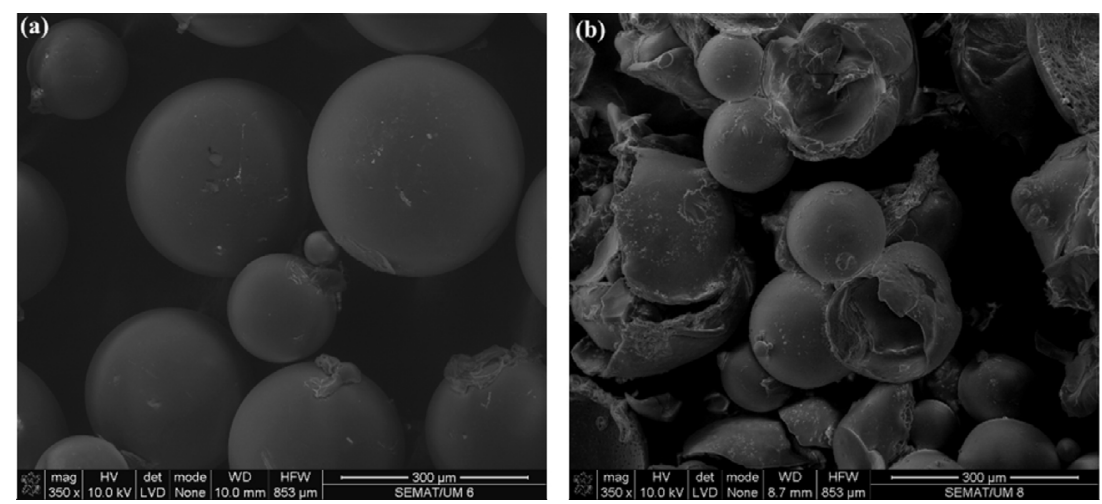

Fig. 11. Scanning electron microscopy micrographs of citronella-loaded polyurethane microcapsules (a) before and (b) after mechanical stress. 
Table 4

Median number of eggs present in the water and microcapsules suspensions for the different tests performed.

\begin{tabular}{|c|c|c|c|c|c|}
\hline Dose & Laying substrate & Median & $\mathrm{Sd}$ & Student's $t$-test & $p$ \\
\hline $30 \%$ & $\begin{array}{l}\text { Water } \\
\text { Suspension }\end{array}$ & $\begin{array}{l}343.7 \\
0.0\end{array}$ & $\begin{array}{l}40.8 \\
0.0\end{array}$ & ss & SS \\
\hline $15 \%$ & $\begin{array}{l}\text { Water } \\
\text { Suspension }\end{array}$ & $\begin{array}{l}264.7 \\
0.0\end{array}$ & $\begin{array}{l}242.2 \\
0.0\end{array}$ & ss & SS \\
\hline $7.5 \%$ & $\begin{array}{l}\text { Water } \\
\text { Suspension }\end{array}$ & $\begin{array}{l}490.7 \\
24.3\end{array}$ & $\begin{array}{l}55.4 \\
37.9\end{array}$ & 12.035 & 0.0005 \\
\hline
\end{tabular}

Sd: standard deviation; ss: not performed due to lack of statistical significance.

Table 5

IRE and BFI values obtained in the four tests.

\begin{tabular}{|c|c|c|c|c|c|c|}
\hline Test number & IRE & $\chi^{2}$ & $p$ & $\mathrm{BFI}$ & $\chi^{2}$ & $p$ \\
\hline 1 & 84.57 & 30.85 & $<0.0001$ & 92.65 & 11.73 & 0.0006 \\
\hline 2 & 100 & ss & ss & 100 & ss & ss \\
\hline 3 & 70.70 & 5.53 & 0.0187 & 58.79 & 1.942 & 0.163 \\
\hline 4 & 76.77 & 50.48 & 0.0001 & 82.55 & 7.076 & 0.0078 \\
\hline
\end{tabular}

ss: not performed due to lack of statistical significance.

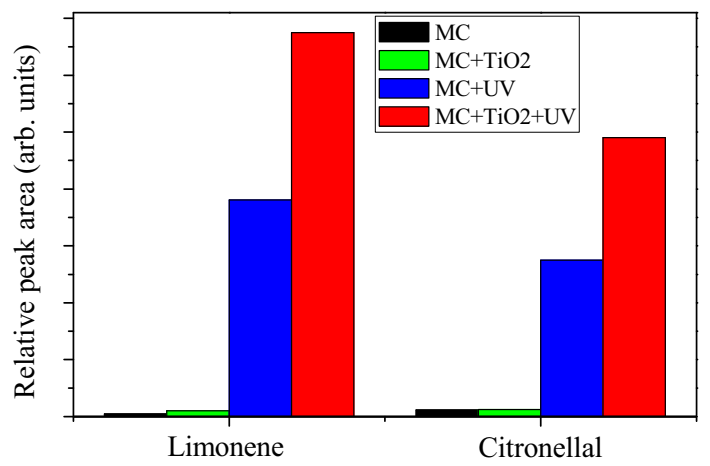

Fig. 13. Peak area of citronella output (from the GC-MS experiments in Fig. 12) for the different tested samples.

From the analysis of Fig. 13 it can be observed that in dark conditions the citronella output from the microcapsules with and without decorated $\mathrm{TiO}_{2}$ nanoparticles is very small. However, submitting the undecorated microcapsules to UV radiation increases the output by 2 orders, due to the capability that ultraviolet radiation has to degrade polymer chains, thus rupturing the microcapsule wall and yielding its release. However, a noticeable effect is registered when functionalizing the microcapsule surface with titanium dioxide nanoparticles and submitting these structures to ultraviolet radiation: the citronella yield is doubled, when compared to the undecorated capsules. This fact proves that titanium dioxide has, in fact, the ability to accelerate the degradation of the microcapsule wall upon UV-A irradiation, hence promoting the release of its content.

\subsection{In-vitro analysis}

\subsubsection{Laying deterrent effect}

From the analysis of the mosquito laying deterrent effect, the data presented in Table 4 suggests that the microcapsules have a mosquito egg laying dissuasion capacity. In fact as the dose of photocatalytic microcapsules loaded with citronella oil, which was dispersed in the Petri dishes containing dechlorinated tap water, increased from $7.5 \%$ to $30 \%$ the egg laying was inhibited, when compared to all control dishes (water without microcapsules). However, this dissuasion ability might be related to the physical properties of the suspension, and as another type of tests must be
Table 6

Percentage of females that reached compartment B, at control and test tunnels.

\begin{tabular}{lllll}
\hline Tunnel & \multicolumn{4}{l}{ Experiment number } \\
\cline { 2 - 5 } & 1 & 2 & 3 & 4 \\
\hline Control & $37.0 \%$ & $10.7 \%$ & $15.0 \%$ & $64.5 \%$ \\
Test & $5.7 \%$ & $0.0 \%$ & $4.4 \%$ & $15.0 \%$ \\
\hline
\end{tabular}

conducted to properly draw a conclusion, as it is presented in the next section.

\subsubsection{Tunnel system repellent tests}

Tunnel tests were performed with the same type of mosquitoes used in the previous section experiments in order to evaluate their repellent and blood feeding from a test rat inhibition. The data shown in Table 5 presents IRE and BFI values above $50 \%$, the critical value above which a product is considered efficient [29]. Statistically, IRE shows significant differences between the numbers of captured females at compartment B in the test tunnel compared to the control tunnel. As for the BFI, although the best results was obtained in test number 2 (BFI: $100 \%$; IRE: $100 \%$ ), only $10.7 \%$ of females reached compartment $B$ in the control tunnel (as seen in Table 6), thus these results were discarded. Despite a BFI index superior to $50 \%$ in test number 3 , there were no statistically significant differences in the number of captured females between control and test $(p>0.05)$. Test number 1 provided the best repellence results, where only $5.7 \%$ of the female mosquitoes reached compartment B in the test tunnel, when compared to $37.0 \%$ that

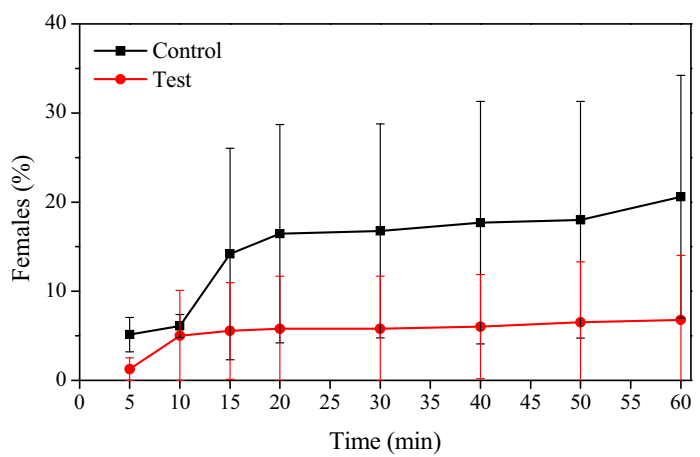

Fig. 14. Mean percentage $( \pm S d)$ of females that reach compartment $B$, in the control and test tunnels. 
reached compartment B at the control tunnel. Fig. 14 shows the median percentage, and respective standard deviation, of females that reached compartment $B$ at different times during the tests. It is apparent that the number of females reaching compartment $B$ in the control tunnel box increases with time, while for the test tunnel this number is practically constant.

\section{Conclusions}

$\mathrm{TiO}_{2}$ nanoparticles with a crystallite size of the order of $10 \mathrm{~nm}$ and a specific surface area $>250 \mathrm{~m}^{2} /$ g were prepared using a modified sol-gel method followed by a hydrothermal treatment at $200^{\circ} \mathrm{C}$. The effect of $\mathrm{pH}$ during synthesis was studied, being the nanoparticles synthetized at $\mathrm{pH}=9$ the ones with the highest photocatalytic activity. It is believed that the alkaline $\mathrm{pH}$ confers a negative charge to the nanoparticles surface, attracting the positively charge methylene-blue molecules. An attempt to dope the $\mathrm{TiO}_{2}$ nanoparticles with nitrogen was also carried out, by the addition of ethylene diamine during synthesis. Despite the slightly higher band gap energy of the doped $\mathrm{TiO}_{2}$ nanoparticles, when compared to the undoped ones, it is indicative that nitrogen substitutional doping in the $\mathrm{TiO}_{2}$ lattice was not optimized, despite the fact that the doped particles at $\mathrm{pH}=9$ revealed enhanced photocatalytic kinetics. Furthermore, these $\mathrm{N}$-doped nanoparticles showed a higher photocatalytic activity than the commercially available Evonik P25, making this synthesis method very promising.

The polyurethane microcapsules proved to be very strong mechanically, while being relatively easy to manufacture. The microcapsules showed a significant release of the encapsulated product when functionalized on its external surface with the modified titanium dioxide nanoparticles and submitted to ultraviolet irradiation, confirming that these nanoparticles can act as a release trigger when the capsules are submitted to UV irradiation. Invitro tests showed some promising results, as the mosquitoes preferred to lay their eggs in water, avoiding the water/citronellaloaded photocatalytic microcapsules suspension. Moreover, in tests where mosquitoes were separated from a feeding source using a perforated textile (uncoated and coated with citronella-loaded photocatalytic microcapsules), it was shown that the number of mosquitoes passing through the untreated textile in order to feed was much greater than in the treated textile.

The high photocatalytic activity of the nanoparticles coupled with the good mechanical resistance and overall quality of the microcapsules, and the ability to control the release of the active agent prompted us to continue this work as this technology is very promising.

\section{Acknowledgements}

This work was supported by FEDER through the COMPETE Program and by the Portuguese Foundation for Science and Technology (FCT) in the framework of the PTDC/CTM-NAN/119979/2010 project. Juliana Marques acknowledges the FCT support for her PhD grant SFRH/BD/112868/2015. The authors would like to acknowledge $\mathrm{Dr}$ C. Mateos-Pedrero for the BET surface area analysis.

\section{References}

[1] R. Dubey, T.C. Shami, K.U. Bhasker Rao, Def. Sci. J. 59 (2009) 82-95.

[2] S.K. Ghosh, Functional Coatings: By Polymer Microencapsulation, 2006, pp. $12-28$.

[3] H. Nigam, A.M. Tamboli, M.S.M. Nainar, Int. J. Res. Pharm. Biomed. Sci. 2 (2011) 474-481

[4] E. Mathiowitz, M. Kreitz, in: Encyclopedia of Controlled Drug Delivery, 1st ed., Wiley, New York, 1999, pp. 493-504.

[5] C. Teixeira, Microencapsulation of perfumes for application in textile industry (Master Thesis), Department of Chemical Engineering, Faculty of Engeneering, University of Porto, Porto, Portugal, 2010.

[6] K. Keyan, T. Ramachandran, O.L. Shamugasundaram, M. Balasubramaniam, T. Ragavendra, J. Text. Apparel Technol. Manag. 7 (2012) 1-10.

[7] Y.Y. Yang, H.H. Chia, T.S. Chung, J. Control. Rel. 69 (2000) 81-96.

[8] Y.Y. Yang, T.S. Chung, N. Ping Ng, Biomaterials 22 (2001) 231-241.

[9] G. Hausberger, P. DeLuca, J. Pharm. Biomed. Anal. 13 (1995) 747-760.

[10] R. Arshady, Polym. Eng. Sci. 30 (1990) 915-924.

[11] W.J. Luo, W. Yang, S. Jiang, J.M. Feng, M.B. Yang, Polym. Degrad. Stabil. 92 (2007) 1359-1364.

[12] H.Y. Lee, S.J. Lee, I.W. Cheong, J.H. Kim, J. Microencapsul. 19 (2002) 559-569.

[13] E.N. Brown, M.R. Kessler, N.R. Sottos, S.R. White, J. Microencapsul. 20 (2003) 719-730.

[14] Y. Frere, L. Danicher, P. Gramain, Eur. Polym. J. 34 (1998) 193-199.

[15] K. Bouchemal, S. Briançon, P. Chaumont, H. Fessi, N. Zydowicz, J. Microencapsul. 20 (2003) 637-651.

[16] C. Guo, L. Zhou, J. Lv, Polym. Polym. Compos. 21 (2013) 449-456.

[17] A. Toubeli, C. Kiparissides, J. Membr. Sci. 146 (1998) 15-29.

[18] M. Brown, A.A. Hebert, J. Am. Acad. Dermatol. 36 (1997) 243-249.

[19] U. Sakulku, O. Nuchuchua, N. Uawongyart, S. Puttipipatkhachorn, A. Soottitantawat, U. Ruktanonchai, Int. J. Pharm. 372 (2009) 105-111.

[20] A. Mills, J. Wang, J. Photochem. Photobiol. A: Chem. 127 (1999) $123-134$.

[21] M. Salehi, H. Hashemipour, M. Mirzaee, Am. J. Environ. Eng. 2 (2012) 1-7.

[22] L. Gao, S. Yang, J. Am. Ceram. Soc. 90 (2007) 1309-1311.

[23] C.H. Wu, J.M. Chern, Ind. Eng. Chem. Res. 45 (2006) 6450-6457.

[24] K.I. Ishibashi, A. Fujishima, T. Watanabe, K. Hashimoto, Electrochem. Commun. 2 (2000) 207-210.

[25] C. Pennetier, V. Corbel, P. Boko, A. Odjo, R. N'Guessan, B. Lapied, J.-M. Hougard, Malar. J. 6 (2007) 38.

[26] R. N'Guessan, B. Knolsc, C. Pennetier, M. Rowland, R. Soc. Trop. Med. Hyg. 102 (2008) 259-262.

[27] K.S.W. Sing, Pure Appl. Chem. 57 (1985) 603-619.

[28] R. Simkovitch, D. Huppert, J. Phys. Chem. B 119 (2015) 14683-14696.

[29] G.C. Müller, A. Junnila, J. Butler, V.D. Kravchenko, E.E. Revay, R.W. Weiss, Y. Schlein, J. Vector Ecol. 34 (2009) 2-8. 